\title{
Dynamic Computation of Incentive Salience: "Wanting" What Was Never "Liked"
}

\author{
Amy J. Tindell, Kyle S. Smith, Kent C. Berridge, and J. Wayne Aldridge \\ Department of Psychology, University of Michigan, Ann Arbor, Michigan 48109-1043
}

\begin{abstract}
Pavlovian cues for rewards become endowed with incentive salience, guiding "wanting" to their learned reward. Usually, cues are "wanted" only if their rewards have ever been "liked," but here we show that mesocorticolimbic systems can recompute "wanting" de novo by integrating novel physiological signals with a cue's preexisting associations to an outcome that lacked hedonic value. That is, a cue's incentive salience can be recomputed adaptively. We demonstrate that this recomputation is encoded in neural signals coursing through the ventral pallidum. Ventral pallidum neurons do not ordinarily fire vigorously to a cue that predicts the previously "disliked" taste of intense salt, although they do fire to a cue that predicts the taste of previously "liked" sucrose. Yet we show that neural firing rises dramatically to the salt cue immediately and selectively when that cue is encountered in a never-before-experienced state of physiological salt depletion. Crucially, robust neural firing to the salt cue occurred the first time it was encountered in the new depletion state (in cue-only extinction trials), even before its associated intense saltiness has ever been tasted as positively "liked" (salt taste had always been "disliked" before). The amplification of incentive salience did not require additional learning about the cue or the newly positive salt taste. Thus dynamic recomputation of cue-triggered "wanting" signals can occur in real time at the moment of cue re-encounter by combining previously learned Pavlovian associations with novel physiological information about a current state of specific appetite.
\end{abstract}

\section{Introduction}

When attributed with incentive salience, learned reward cues (Pavlovian conditioned stimuli; CSs) can trigger "wanting" for their reward (unconditioned stimulus; UCS) and become attractive "motivational magnets" (Toates, 1986; Robinson and Berridge, 1993; Dickinson and Balleine, 2002; Mahler and Berridge, 2009). Incentive salience at a given moment depends on current physiological state as well as on learned associative values of a cue. For example, a cue for ice cream may have greater motivational pull ("wanting") when the perceiver is hungry or hot.

Natural appetites (e.g., thirst, hunger, salt appetite) and some drug states (e.g., intoxication priming, long-term sensitization) potentiate the intensity of cue-triggered "wanting" for relevant rewards (e.g., hunger potentiates food cues) (Toates, 1986; Berridge, 2001; Tindell et al., 2005; Mahler and Berridge, 2009). Interestingly, in some new physiological states, enhanced "wanting" may occur the first time a relevant CS is reencountered even before the reward UCS itself is experienced in the new state (Toates, 1986; Robinson and Berridge, 2003; Ber-

Received May 28, 2009; revised Aug. 6, 2009; accepted Aug. 24, 2009.

The research was supported by National Institutes of Health (NIH) Grants DA015188, DA017752, and MH63649 (J.W.A., K.C.B.), National Science Foundation Fellowship (A.J.T.), and NIH Training Grant DC00011 (K.S.S.). We acknowledge the assistance of Jonathan Lee for computational data analysis and manuscript preparation, and Drew Thodeson and Nadia Siddiqui for experimental assistance. We also acknowledge our colleague Jun Zhang, who developed the computational model described here.

Correspondence should be addressed to J. Wayne Aldridge, Department of Psychology, University of Michigan, 525 East University Street, Ann Arbor, Ml 48109-1043. E-mail: jwaynea@umich.edu.

K. S. Smith's present address: McGovern Institute for Brain Research, Massachusetts Institute of Technology, 46-6133 77 Massachusetts Avenue, Cambridge, MA 02139.

DOI:10.1523/JNEUROSCI.2499-09.2009

Copyright $\odot 2009$ Society for Neuroscience $\quad$ 0270-6474/09/2912220-09\$15.00/0 ridge, 2004). Salt appetite provides a good example (Cannon, 1932; Richter, 1956). When rats are sodium depleted, they will press a salt-associated lever or approach or consume a bitter/sour $\mathrm{CS}$ previously associated with intense salt $(\mathrm{NaCl})$. They may do this even if the actual salt UCS is absent and has never yet been retasted as "liked" (Krieckhaus and Wolf, 1968; Fudim, 1978; Berridge and Schulkin, 1989; Schulkin, 1991), and even if they remain incapable of more cognitive act-outcome inferences before retasting (Dickinson, 1986; Dickinson and Dawson, 1987).

According to the incentive salience hypothesis, this anticipatory motivational revaluation occurs because the Pavlovian CS has acquired incentive-relevant features of its UCS, allowing the CS to interact with physiological states as would its UCS (Bindra, 1978; Toates, 1986; Dickinson and Balleine, 2002; Berridge, 2004). In other words, CS incentive salience is a computational product that dynamically combines learned CS-UCS associations with current relevant physiological states (Robinson and Berridge, 1993; Berridge, 2001, 2007; Zhang et al., 2009). Modulation of incentive salience adaptively guides motivated behavior to appropriate rewards. However, when the underlying brain circuitry goes awry, such as in addiction, excessive "wanting" and compulsive pursuit of rewards may result (Everitt and Wolf, 2002; Robinson and Berridge, 2003).

The neural basis for the dynamic recomputation of incentive salience is still unknown. Here we focus on mesocorticolimbic signals that pass through the ventral pallidum (VP), a critical circuit in reward and addiction (Lim et al., 2004; Kalivas and Volkow, 2005; Tang et al., 2005; Heimer and Van Hoesen, 2006; Zahm, 2006; Pessiglione et al., 2007; Mickiewicz et al., 2009; Smith et al., 2009). Ventral pallidum firing patterns encode the incentive salience of Pavlovian cues that predict hedonic rewards, 


\section{Training and "CS Plus UCS" Trials}

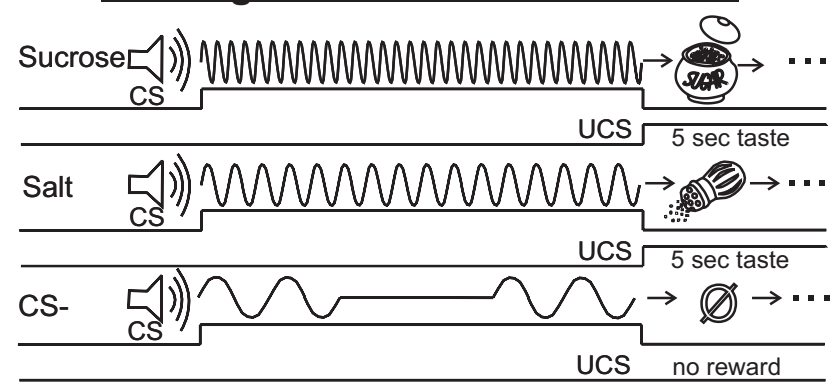

\section{Extinction - "CS Only" Trials}

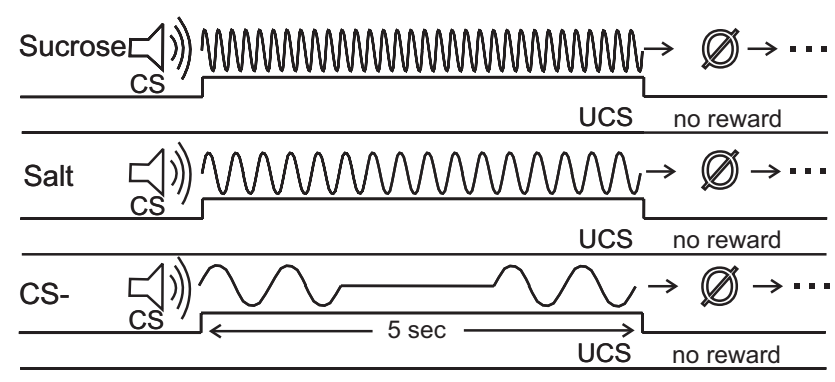

\section{Test Blocks: CS-, "CS Only", "CS Plus UCS"}

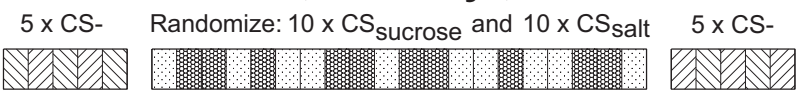

Figure 1. Methods: $\mathrm{A} 5$ s tone cue $\left(\mathrm{CS}_{\text {sucrose }}\right)$ predicted an infusion of sucrose solution into the mouth as UCS. A different tone cue $\left(\mathrm{CS}_{\text {salt }}\right)$ predicted concentrated $\mathrm{NaCl}$ taste infusion. A third tone (CS-) predicted no infusion. Tones were counterbalanced between animals. Trials with actual tastes, used for training and phase 2 of testing, are shown at the top ("CS plus UCS"). Each test day began with an extinction phase ("CS only," middle) and was identical except that the CS tones were not followed by UCS taste infusions. At the beginning of each test phase (bottom time line), 5 (S - control cues were presented, followed by 10 sucrose and salt trials in a random mix, followed by 5 more CS - control trials. The experiment consisted of two test days: (1) normal homeostasis and (2) sodium-depleted. Time axis truncated and not to scale.

and the modulation of reward impact by physiological states (Tindell et al., 2004, 2005, 2006).

Our question here was the following: can dynamic recomputation of incentive salience be detected in ventral pallidal neural activity correlated to cue presentation? We show that it can.

\section{Materials and Methods}

To test whether signals for dynamically recomputed incentive salience are carried in VP circuits, we recorded VP neural responses and behavioral affective reactions to cues and tastes in rats that had learned Pavlovian associations between auditory predictive cues (CSs) and oral infusions of fluids containing either sucrose or intense $\mathrm{NaCl}$ (UCSs). One auditory cue $\left(\mathrm{CS}_{\text {salt }}\right)$ predicted a taste infusion directly into the mouth of a "disliked" intense salt UCS ( $1.5 \mathrm{M} \mathrm{NaCl}$ : an aversive concentration three times higher than seawater or an order of magnitude above isotonic). Another auditory tone $\left(\mathrm{CS}_{\text {sucrose }}\right)$ predicted infusion of a "liked" $0.5 \mathrm{M}$ sucrose UCS. A third control tone (CS-) predicted no UCS (Fig. 1). Recording took place on two separate days: once in normal physiological homeostasis, and $24 \mathrm{~h}$ later in a novel sodium-depleted state of salt appetite (induced overnight). Neural activity was recorded on one day in normal homeostasis and on another day after sodium depletion, using multiwire electrodes implanted into the posterior portion of the VP. The posterior VP was targeted because previous studies showed it contains a $1 \mathrm{~mm}^{3}$ "hedonic hotspot" where $\mu$ opioid stimulation causes increase in "wanting" and "liking" for food rewards, and where neuronal firing codes the motivational value of CSs that predict reward, as well as the hedonic impact of UCS taste rewards (Tindell et al., 2004, 2005, 2006; Smith and Berridge, 2005, 2007; Smith et al., 2007). Rats had never before experienced a salt appetite before the depletion test.

To ensure that we were isolating the dynamic motivational value of the cues alone on a given test day (uncontaminated by any accompanying unconditioned reward), each recording session began with extinction trials (CSs presented with no reward UCSs; "CS only" trials) (Fig. 1), No UCS stimulus fluid was delivered to the rat during extinction trials. Subsequently, a second series of trials with actual tastes ("CS plus UCS" trials) (Fig. 1) was presented on the same days to confirm the increase in palatability of $\mathrm{NaCl}$ taste by assessing behavioral affective orofacial reactions during VP recordings.

Animals. The University Committee on the Use and Care of Animals approved all experimental methods. Male Sprague Dawley rats (300-450 g; $N=18$ ) were maintained on an ad libitum sodium-free diet (Purina) and distilled water. Rats also had ad libitum access to a separate drinking tube containing $0.5 \mathrm{M} \mathrm{NaCl}$ solution (except for the $24 \mathrm{~h}$ period when sodium depletion was being induced). Detailed surgical procedures have been described (Tindell et al., 2006). Briefly, animals were anesthetized with a ketamine/xylazine $(100 \mathrm{mg} / \mathrm{kg} / 10 \mathrm{mg} / \mathrm{kg})$ for sterile, stereotaxic surgery. Bilateral intraoral cannulae for taste infusions were implanted along with multiwire (50 $\mu \mathrm{m}$ tungsten) electrodes into the posterior ventral pallidum (range of recording sites: AP: -0.11 to -1.53 ; ML: 1.8-3.3; DV: 6.8-7.7). This anatomic region encompassed the hedonic hotspot of posterior VP identified by Smith and Berridge (Smith and Berridge, 2005, 2007; Tindell et al., 2006). Anchoring bone screws in the skull served as ground reference electrodes. Animals were allowed $7 \mathrm{~d}$ to recover before training and testing began.

Pavlovian training. Training and testing was conducted in a $25 \mathrm{~cm}$ cylinder with a glass floor with a mirror underneath for video recording orofacial taste reactivity and other behavior. A laboratory computer program controlled cue (conditioned stimulus, "CS") and reward (unconditioned stimulus, "UCS") presentations. Rats received five training sessions in which they learned discriminative associations between three distinct auditory cues (Fig. 1). Two $5 \mathrm{~s}$ cues predicted oral infusions that began at their offset. A third cue (CS-) predicted nothing. The sucrose or salt taste infusion $(0.1 \mathrm{ml}$ per infusion at $0.02 \mathrm{ml} / \mathrm{s})$ lasted for $5 \mathrm{~s}$. The " $\mathrm{CS}_{\text {salt }}$ cue" predicted a concentrated $\mathrm{NaCl}$ infusion $(1.5 \mathrm{M})$. A different " $\mathrm{CS}_{\text {sucrose }}$ cue" predicted sucrose infusion ( $0.5 \mathrm{M}$ concentration). For each rat, CS assignments were counterbalanced between a $400 \mathrm{~Hz}, 0.75 \mathrm{~s}$ on/off pulsed tone; a $3800 \mathrm{~Hz}$, continuous tone; and a $8000 \mathrm{~Hz}, 0.1 \mathrm{~s}$ on/off pulsed tone. Ten pairs each of sucrose cue/infusion and salt cue/ infusion were presented randomly (Fig. 1) on a variable intertrial interval with a mean value of $1 \mathrm{~min}$. Each session began and ended with presentation of five CS- cues under the same intertrial interval schedule to bracket the block of $20 \mathrm{CS}+\left(10 \mathrm{CS}_{\text {salt }}\right.$ and $\mathrm{CS}_{\text {sucrose }}$ in random order). There was no gap between the CS + and CS - blocks other than the $1 \mathrm{~min}$ intertrial interval. The bracket design presented CS + blocks and CSblocks in a balanced ABBA pattern $\left(\mathrm{CS}-\right.$, random $\mathrm{CS}_{\text {salt }}$ or $\mathrm{CS}_{\text {sucrose }}$, $\mathrm{CS}-$ ) to rule out gradual drift in neural firing over the trial.

Testing and recording. Neural activity was recorded in two sessions spaced $24 \mathrm{~h}$ apart. On day 1 , rats were in normal homeostasis; on day 2, rats were in sodium appetite. A syringe containing sucrose or $\mathrm{NaCl}$ solution was connected to the intraoral delivery tube so as to create a dead space (extending over $\sim 2 \mathrm{~cm}$ of tubing) visible as an air bubble in front of an advancing UCS solution. This bubble, which could be seen clearly through the translucent delivery tube, marked the onset point of the advancing UCS solution. During extinction testing, the position of this bubble space was monitored carefully to be sure that no solution would enter the rat's mouth until later trials when the pump was turned on. The bubble blocked fluid delivery until the beginning of the reinforced CS-UCS session when the syringe pump was activated to advance the solution. As in training, each test day began with five CS - presentations (Fig. 1). Those were followed by the extinction block of CS + alone trials (unaccompanied by UCS). A block of CS-UCS reinforced trials followed, followed by another block of CS - trials (so that CS - presentations bracketed all CS + and UCS presentations, occurring both before and after them). A $10 \mathrm{~min}$ period was imposed between each block. 
We emphasize that the CS+ extinction block was the most important test block for assessing dynamic recomputations: it contained $20 \mathrm{CS}+$ trials in random order $\left(10 \mathrm{CS}_{\text {salt }}\right.$ and $10 \mathrm{CS}_{\text {sucrose }}$ ), in which $\mathrm{CS}+\mathrm{s}$ occurred alone without accompanying UCS taste infusions ("CS only" trials) (Fig. 1). Thus crucially, in extinction tests, rats did not taste any UCS. Instead, rats had only associative information based on previous CS-UCS experiences of $\mathrm{CS}_{\text {salt }}$ obtained from pairings on previous days. On those previous days animals were in normal physiological state and thus the association with $\mathrm{NaCl}$ tastes had been aversive (i.e., "disliked"). In the second phase of each test day, actual taste rewards followed the appropriate cues ("CS plus UCS"). $\mathrm{CS}_{\text {salt }}$ and $\mathrm{CS}_{\text {sucrose }}$ trials were intermixed randomly in both phases (10 each) (Fig. 1, bottom).

Salt depletion procedure. Sodium appetite was induced by a combined regimen of the diuretic furosemide (to promote sodium loss and stimulate angiotensin II production), the mineralocorticoid hormone deoxycortisone acetate (to mimic aldosterone elevation), and a sodium-free diet (to prevent sodium replacement). Rats received a subcutaneous injection of $7.5 \mathrm{mg} / \mathrm{kg}$ furosemide and $5 \mathrm{mg} / \mathrm{kg}$ deoxycortisone acetate immediately after testing on day 1 (Flynn et al., 2002), followed $2 \mathrm{~h}$ later by an additional injection of $7.5 \mathrm{mg} / \mathrm{kg}$ furosemide (Tamura and Norgren, 1997). $\mathrm{NaCl}$ was removed from the home cage after the first injection and not replaced for the next $24 \mathrm{~h}$. Sodium-free chow (Purina) and distilled water were maintained. We previously found this regimen induces a robust salt appetite over $24 \mathrm{~h}$ that is sufficiently strong to cause "disliked" $1.0 \mathrm{M} \mathrm{NaCl}$ taste $\mathrm{NaCl}$ taste to become positively "liked" and elevate $\mathrm{NaCl}$-elicited VP firing (Tindell et al., 2006). Salt appetite induction was subsequently verified after neural recording by measuring consumption of $0.5 \mathrm{M} \mathrm{NaCl}$ solution in the home cage, which was returned after testing on day 2 , and which also served to restore normal sodium balance. A $2000 \%$ increase in $24 \mathrm{~h}$ intake of $0.5 \mathrm{M} \mathrm{NaCl}$ (mean intake: day $1=1 \mathrm{ml}$; day $2=$ $\left.22 \mathrm{ml} ; t_{(15)}=9.27, p<0.001\right)$ confirmed the salt appetite and enhancement of $\mathrm{NaCl}$ "wanting."

Taste reactivity analysis. Taste reactivity (TR) responses to CS and to UCS were evaluated offline in a slow-motion, frame-by-frame video analysis (Berridge, 2000; Tindell et al., 2006). Experimenters blind to condition scored hedonic "liking," aversive "disliking," and neutral orofacial movements elicited by CS cues ( $5 \mathrm{~s}$ ) and UCS tastes ( $5 \mathrm{~s}$ infusion, followed by an additional $5 \mathrm{~s}$ period to capture after-reactions). Hedonic responses included rhythmic midline tongue protrusions, lateral tongue protrusions, and paw licking. Aversive responses included gapes, headshakes, chin rubs, and forelimb flails. Neutral responses included rhythmic mouth movements and grooming (Grill et al., 1992). Behaviors that typically occur in discrete events, including lateral tongue protrusions, gapes, headshakes, chin rubs, and forelimb flails were counted each time they occurred. Behaviors that occur in continuous bouts (rhythmic tongue protrusions, paw licking, rhythmic mouth movements, grooming) were timed in seconds.

Hedonic/aversive reactions were summed into affective categories to form an overall positive hedonic "liking" score and a negative aversive "disliking" score. Other behaviors, including orientation toward CS cues (rearing, approach, head turns), grooming movements (mouth, limbs) were totaled separately. Mixed-design ANOVAs (day = between subject, taste $=$ within subject) and Bonferroni-corrected post hoc tests were performed to evaluate effects of the cues $\left(\mathrm{CS}_{\text {salt }}, \mathrm{CS}_{\text {sucrose }}\right.$, CS - ), UCS tastes (salt, sucrose), and physiological condition (baseline-replete, depletion, rerepletion) on taste reactivity and other behavioral responses. Latencies to the first unconditioned response after infusion onset were also compared across tastes and test sessions using ANOVA.

Neural analysis. Neural units were separated from each other and background noise with Offline Sorter (Plexon). Unit activity was ana- lyzed with NeuroExplorer (Nex Technologies). Single unit adherence was verified by distinct spike waveforms and clear refractory periods in an autocorrelation histogram. Cross-correlation analyses were performed to ensure that all neurons were counted only once in the analyses. We did not presume that the same individual units were recorded on separate days, but instead compared data as though different units were recorded on different days, because of the impossibility of being certain of neuronal identity across sessions. We adapted this conservative group design approach for all analyses described below.

Firing changes in response to CS cues were computed for each trial in a bin $500 \mathrm{~ms}$ wide beginning at the onset of the CS cue. For response to tastes, a $5 \mathrm{~s}$ bin began at the onset of taste infusion period (or temporally matched period in extinction trials that had no infusion). Firing rate changes in each trial were normalized by dividing by baseline rate (average across trials of $5 \mathrm{~s}$ period before cue). A neuron was defined as responsive to a cue or taste if the firing rate across trials during the examined bin was significantly different $(p<0.05$ in Bonferronicorrected paired $t$ tests) from the average firing rate during background ( $5 \mathrm{~s}$ before infusion).

To assess firing rate effects, we averaged the normalized firing rate for each responsive unit across trials (except when comparing trial effects explicitly), and compared response magnitudes across stimuli and test days using mixed-measures ANOVA (day/state was treated as a betweensubjects factor because of uncertainty of whether the same neurons were recorded on different days; stimuli comparisons on the same day were treated as a within-subject factor); post hoc comparisons were conducted by Bonferroni-corrected tests.

For population comparisons, numbers of neurons activated by the cues and/or tastes were tallied for a binomial analysis and compared across extinction versus normal trials and physiological conditions using ANOVAs.

Histology. After recordings were completed, rats were given an overdose of pentobarbital, and perfused transcardially with saline and formaldehyde. Brains were removed, sliced in $40 \mu \mathrm{m}$ coronal sections, and stained with cresyl violet. Slices were examined under a microscope to verify electrode placement in VP, and electrode sites were mapped onto a computerized brain atlas (Paxinos and Watson, 2007).

\section{Results}

\section{Neural coding in ventral pallidum}

Most VP neurons responded phasically to auditory CS cues, rising within $100 \mathrm{~ms}$ of tone onset and decaying nearly back to baseline by $500 \mathrm{~ms}$, although the physical tone continued another $4.5 \mathrm{~s}$ (Fig. 2). Even in extinction presentations of a CS by itself, $52 \%$ of neurons $(66 / 128)$ were activated by a CS during the first 
Normal Homeostasis

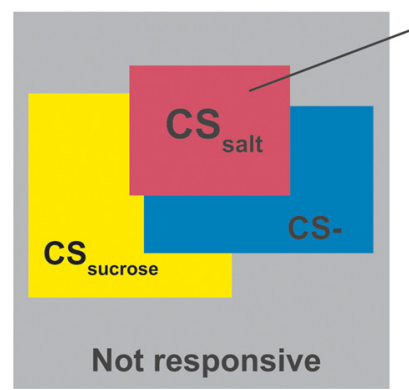

Salt Depleted

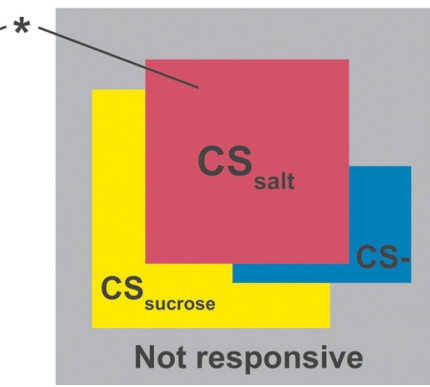

Figure 3. Population coding during extinction testing ("CS alone"). This "Venn-style" diagram uses rectangles rather than circles to represent sizes of neural populations responsive to the different cues $\left(\mathrm{CS}_{\text {salt },}, \mathrm{CS}_{\text {sucrose }}\right.$ and $\left.\mathrm{CS}-\right)$. The area of each rectangle is proportional to the population size. The gray background represents the total of all neurons tested and the area of exposed gray represents the proportion of unresponsive neurons. The overlap between rectangles indicates the intersection among populations with one, two or, three responses. For example, the overlap between red and blue rectangles represents the proportion of neurons with responses to both $\mathrm{CS}_{\text {salt }}$ and $\mathrm{CS}-$. Unique responses overlap gray background alone. Normal homeostasis test day is on the left and test after salt depletion is on the right. Only the proportion of neurons responsive to salt cues grew on the salt depletion test day $\left({ }^{*} p<0.05, \chi^{2}\right.$ test of independence) (Siegel, 1956).

\begin{tabular}{|c|c|c|c|}
\hline & Overall & Homeostatic & Salt depleted \\
\hline \multicolumn{4}{|c|}{ Extinction CS-only trials ${ }^{a}$} \\
\hline $\mathrm{CS}_{\text {sucrose }}$ & $46 / 128$ (36\%) & $16 / 56(29 \%)$ & $30 / 72(42 \%)$ \\
\hline $\mathrm{CS}_{\text {salt }}$ & $30 / 128(23 \%)$ & $8 / 56(14 \%)$ & $22 / 72(31 \%)$ \\
\hline$C S-$ & $24 / 128(19 \%)$ & $11 / 56(21 \%)$ & $13 / 72(18 \%)$ \\
\hline \multicolumn{4}{|c|}{ Paired CS + with UCS trials $s^{b}$} \\
\hline $\mathrm{CS}_{\text {sucrose }}$ & $51 / 123(41 \%)$ & $27 / 63(43 \%)$ & $24 / 60(40 \%)$ \\
\hline $\mathrm{CS}_{\text {salt }}$ & 49/123 (40\%) & $21 / 63(33 \%)$ & $28 / 60(47 \%)$ \\
\hline $\mathrm{CS}_{-}$ & $24 / 123(20 \%)$ & $13 / 63(21 \%)$ & $11 / 60(18 \%)$ \\
\hline Sucrose taste & 50/123 (41\%) & $31 / 63(49 \%)$ & $19 / 60(32 \%)$ \\
\hline Salt taste & $45 / 123(37 \%)$ & $13 / 63(21 \%)$ & $32 / 60(53 \%)$ \\
\hline
\end{tabular}

${ }^{a} F_{(2,127)}=10.145, p<0.001 .{ }^{b} F_{(4,122)}=12.367, p<0.001$.

phase of each test. Many neurons were responsive to more than one cue (41\%) (Fig. 3). When cues were followed and reinforced with actual UCS tastes, in the second phase of each test day, the proportion of responsive neurons increased to $79 \%$ (97/123). VP responses to UCS tastes were slower and more prolonged than to CS tones, tending to last for much of the $5 \mathrm{~s}$ duration of the UCS oral infusion. Excitation in firing rate was the predominant response to both CS and UCS stimuli.

Previous studies indicated that at least two neural coding schemes in ventral pallidum may carry information about reward events: firing rates in individual neurons (i.e., rate coding), and recruitment of more participant neurons to enlarge the information-carrying network (i.e., population coding) (Tindell et al., 2004, 2006). We describe population coding data for all stimuli and trials first, and then rate coding for the same stimuli and trials.

\section{Population coding}

Cue populations in extinction trials ("CS only"; no taste infusions) Even though no tastes were delivered in extinction trials ("CS only"), VP neurons responded discriminatively to CS cues ( $46 \%$ of units in homeostasis and 53\% in salt-depleted conditions; main effect of cue across all trials: $\left.F_{(2,127)}=10.145, p<0.001\right)$ (Table 1). In normal homeostasis, the cue that previously predicted sucrose $\left(\mathrm{CS}_{\text {sucrose }}\right)$ activated three times as many neurons as $\mathrm{CS}_{\text {salt }}$ (42\% vs $14 \%$; post hoc $\left.p<0.05, \mathrm{df}=127\right)$. Sodium depletion dramatically changed this relationship by selectively doubling the number of $\mathrm{CS}_{\text {salt }}$-responsive neurons in extinction trials from $14 \%$ on day 1 to $31 \%$ on day 2 ( post hocp $<0.05, \mathrm{df}=$ 127). Only the salt cue population expanded in the novel state. The sucrose cue continued to be a robust stimulus on day 2 during the sodium depletion test, activating $42 \%$ of VP neurons. That proportion was not significantly changed from the proportion observed during $\mathrm{CS}_{\text {sucrose }}$ extinction trials in normal homeostasis on the previous day (no overall interaction: $F_{(2,127)}=$ $1.869, p=0.156$, post hoc $p>0.05, \mathrm{df}=127)$. The control cue (CS-), which predicted no taste, activated $21 \%$ of VP neurons on day 1 and $18 \%$ on day 2 . CS - populations were smaller than the $\mathrm{CS}_{\text {sucrose }}$ population on the normal day, and smaller than both $\mathrm{CS}_{\text {sucrose }}$ and $\mathrm{CS}_{\text {salt }}$ populations on the sodium-depleted day (each post hoc cue comparison $p<0.05, \mathrm{df}=127$ ). Thus, the sizes of VP populations activated by cues coded the incentive value of each CS appropriate to the rats' physiological state on that day. It is important to note that all oral infusions of $\mathrm{NaCl}$ taste had been unpalatable on previous presentations in the normal state, yet the population to the $\mathrm{CS}_{\text {salt }}$ still doubled in the depletion state during its first presentations in extinction.

\section{Populations in reinforced trials with taste infusions} ("CS plus UCS")

In the second phase of testing on each day, UCS infusions followed their CS cues, as in training, to allow assessment of VP coding of sucrose and $\mathrm{NaCl}$ tastes in relation to their predictors. Most neurons were activated by both cues and tastes (67\% across both test days, $N=83 / 123$; main effect: $F_{(4,122)}=$ 12.367, $p<0.001)$.

The size of the population responsive to tastes of salt versus sucrose UCS depended on the physiological state of the day (interaction: $\left.F_{(4,122)}=8.256, p<0.0001\right)$. During normal homeostasis on the day 1 test, sucrose infusions [31/63 (49\%)] activated more than twice as many $\mathrm{VP}$ neurons as $\mathrm{NaCl}$ infusions [13/63 (21\%); post hoc $p=0.001, \mathrm{df}=62]$ (Fig. 3). In contrast, during the sodium depletion test on the next day, the VP population activated by $\mathrm{NaCl}$ infusions more than doubled from the previous normal day [32/60 (53\%)], and was actually 50\% larger than the sucrose population $[19 / 60(32 \%)$; post hoc $p=0.02, \mathrm{df}=$ 60] (Fig. 3). This change replicates our previous report that VP population size codes salt palatability (Tindell et al., 2006), and reflected both an increase in the proportion of neurons responsive to salt tastes on the sodium-depleted test day ( post hoc $p<$ $0.0001, \mathrm{df}=122$ ), and a simultaneous decrease in the proportion of neurons responsive to sucrose tastes ( post hoc $p<0.05, \mathrm{df}=$ 122). Thus, the ventral pallidum population code represented the conversion of concentrated salt solution from a bad taste to a good taste.

\section{Rate coding}

The most dramatic evidence for dynamic recomputation of CS incentive salience came from firing rates of responsive VP neurons, confirming that a VP rate code sensitively represents the incentive salience of reward cues (overall main effect on model: $\left.F_{(4,127)}=4.848, p=0.011\right)$. 
Cue rate responses in extinction trials ("CS only"; no taste infusions)

On the first test day when rats were in normal homeostasis, sucrose cues ( $\left.\mathrm{CS}_{\text {sucrose }}\right)$ evoked brief elevations of firing within 50-100 ms after onset of a CS + tone (Fig. 2). Peak values were reached by $250 \mathrm{~ms}$ and rates declined toward baseline by 500 ms (Figs. 2, 4, 5). In some cells firing rates decreased with $\mathrm{CS}_{\text {sucrose }}$ tone onset. On average though, the initial response was a marked increase that reached nearly $40 \%$ above background ( post hoc $p=0.020$, $\mathrm{df}=25$ ) (Fig. 4a,c). In contrast, the salt cue $\left(\mathrm{CS}_{\text {salt }}\right)$ evoked activity in only $23 \%$ of cells on day 1 normal homeostasis (Table 1). As with sucrose tones both excitation and inhibitions were observed; however with $\mathrm{CS}_{\text {salt }}$ responses, they essentially cancelled each other out so that on average there was no net change in firing rate compared with precue baseline (post hoc $p=0.812, \mathrm{df}=25$ ) (Fig. $4 a, c)$. Rates to the CS - also never significantly changed from baseline. Thus, on day 1 average firing rates to $\mathrm{CS}_{\text {salt }}$ and $\mathrm{CS}-$ were equally low ( post hoc $p=0.367$, df $=25$ ). Firing rates to $\mathrm{CS}_{\text {sucrose, }}$ on the other hand, were higher than either $\mathrm{CS}_{\text {salt }}$ (post hoc $p=$ 0.018 , df $=25)$ or CS - (post hoc $p=$ 0.020 , df $=25$ ).

The $\mathrm{CS}_{\text {sucrose }}$ and $\mathrm{CS}_{\text {salt }}$ rate pattern changed with the induction of the novel sodium depletion state on the second test day. This change was highlighted by a dramatic and selective initial burst of activity to the $\mathrm{CS}_{\text {salt. }}$ The firing rates of this response to the salt cue on the salt appetite day almost doubled from the previous day in normal homeostasis (Fig. 4c) ( post hoc on day $p<0.0001, \mathrm{df}=63$ ). $\mathrm{CS}_{\text {salt }}$ elicited firing rose to $170 \%$ above baseline within $250 \mathrm{~ms}$, and then fell to baseline levels by $500 \mathrm{~ms}$ after tone onset. This phasic response to salt cues resembled the $\mathrm{CS}_{\text {sucrose }}$ peaks, which did not change with salt depletion. On day 2 firing rates to $\mathrm{CS}_{\text {salt }}$ did not differ from $\mathrm{CS}_{\text {sucrose }}$ (post hoc $p=0.220, \mathrm{df}=63$ ) (Fig. 4a-c). Activity evoked by the CS - control tone in sodium-depleted state was similar to normal homeostasis except for a slight but significant increase in rate during the first $500 \mathrm{~ms}$ ( post hoc $p<0.05, \mathrm{df}=$ 63) (Fig. $4 d$ ). This change may indicate some response generalization between the $\mathrm{CS}+\mathrm{s}$ and $\mathrm{CS}-$ tones.

The elevation in firing to $\mathrm{CS}_{\text {salt }}$ was evident even on the first "CS only" trials in extinction testing. For example, on the very first extinction trial after depletion, firing to the $\mathrm{CS}_{\text {salt }}$ was markedly enhanced (154\%) above the level seen for the first presentation in homeostasis the day before (Fig. 5). Firing rate was higher on each of the $10 \mathrm{CS}_{\text {salt }}$ trials in depletion state than in normal homeostasis, though there was a partial decline in normalized firing from trial 1 to trial 10 on both days (Fig. 5) (ANOVA across trial $\left.F_{(9,136)}=2.507, p=0.011\right)$. The immediate and strong response to $\mathrm{CS}_{\text {salt }}$ in the first extinction trials demonstrates that the learned Pavlovian association between $\mathrm{CS}_{\text {salt }}$ and its UCS salt taste could be used to recompute a revised representation for this cue even before UCS salt had been tasted in the new appetite state.

The firing changes evoked by CS tones sometimes persisted at lower plateau levels for $4-5 \mathrm{~s}$ throughout the entire CS presenta-
Extinction Tests "CS Only"

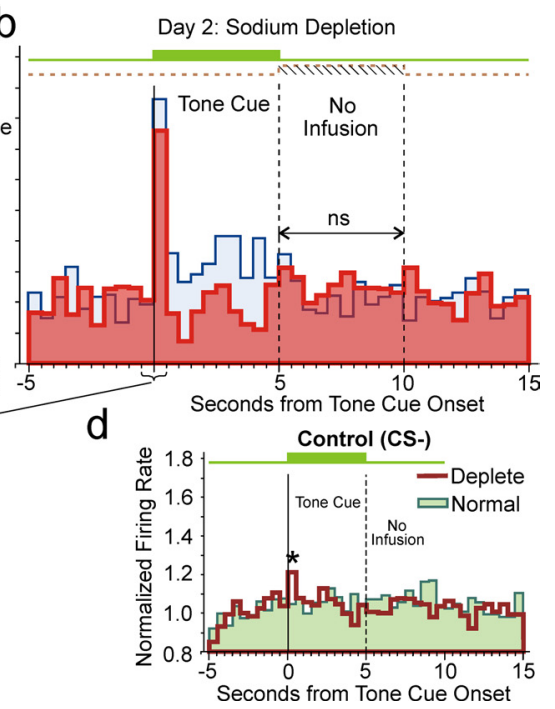

Figure 4. Sodium depletion selectively potentiates an initial burst of activity to $\mathrm{CS}_{\text {salt }}$ in extinction trials. These histograms show from 5 s before cue onset to $15 \mathrm{~s}$ after cue offset; 500 ms bins). $\boldsymbol{b}$, Sodium depletion test on day 2. c, Analysis with 250 ms bins 列 no significant difference during depletion $(\boldsymbol{b})$. $\boldsymbol{d}$, Firing rates to the onset of control cue transiently increase slightly during depletion, but firing rates to $\mathrm{CS}$ - overall are lower than to the other CS cues. "**" indicates significant difference $(p<0.05)$.

\section{$\mathrm{CS}_{\text {salt }}$ Firing Across Extinction}

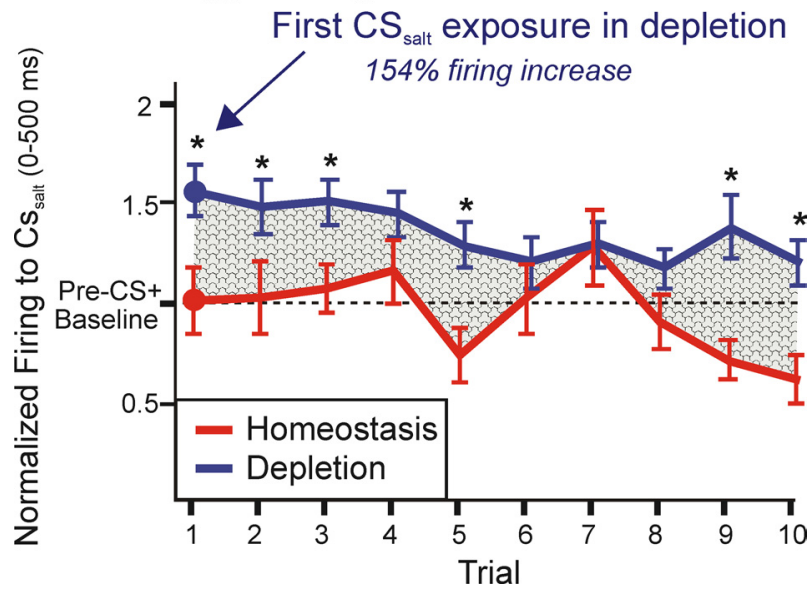

Figure 5. Comparison of VP firing to $\mathrm{CS}_{\text {salt }}$ across extinction trials in normal homeostasis (red) versus salt appetite (blue). Lines depict mean \pm SEM firing (normalized to precue background) across 10 extinction trials. Firing to $C S_{\text {salt }}$ during salt appetite was significantly elevated above normal in the very first trials, including the very first $\mathrm{CS}_{\text {salt }}$ presentation after depletion (trial 1). This firing elevation was generally robust across extinction trials. ${ }^{*} p<0.05$.

tion after the initial phasic $0.5 \mathrm{~s}$ response peak, and those prolonged changes could occur as either excitatory plateaus or inhibitory troughs. For example, the $\mathrm{CS}_{\text {sucrose }}$ elicited a prolonged excitatory plateau lasting $\sim 5 \mathrm{~s}$ on both test days, at a level which was statistically elevated above baseline on the sodium-depleted day $(p<0.0001, \mathrm{df}=38)$ and marginally elevated on the normal homeostatic test day $(p=0.052, \mathrm{df}=25)$. In contrast, on the normal homeostatic test day the $\mathrm{CS}_{\text {salt }}$ elicited an opposite inhib- 
Tone Cues and Tastes - "CS Plus UCS"
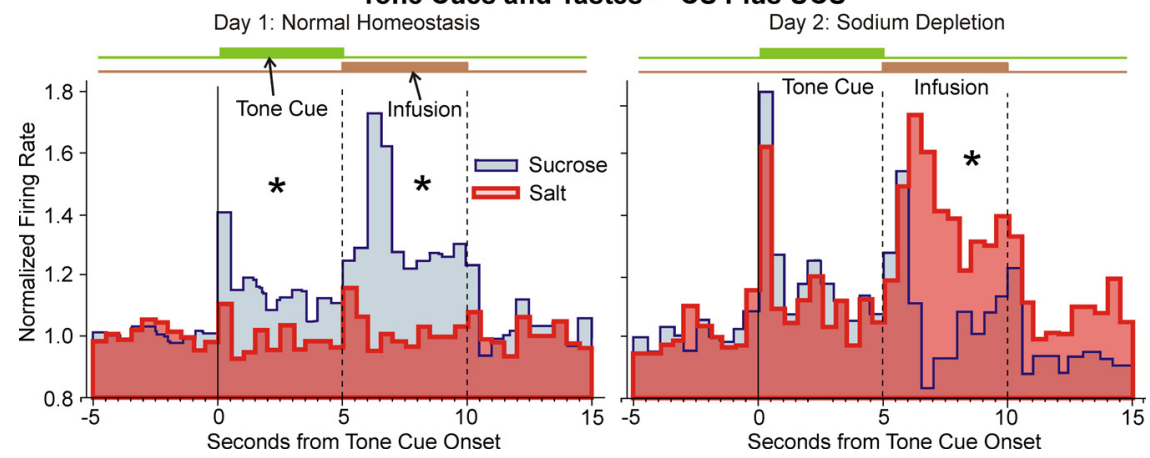

Figure 6. VP firing rate coding of CS and UCS during phase two on day 1 (normal homeostasis) and day 2 (sodium depletion) during trials "CS plus UCS" with actual taste reward infusions. On normal day 1, VP neurons fire to $C S_{\text {sucrose }}$ and to sucrose taste UCS, but not significantly to $\mathrm{CS}_{\text {salt }}$ or salt taste. On sodium-depleted day 2, neurons fire to $\mathrm{CS}_{\text {salt }}$ as well as $\mathrm{CS}_{\text {sucrose' }}$ and fire even more vigorously to salt taste than to sucrose taste. The format follows Figure 4, with the brown line indicating the timing of actual taste infusions. ${ }^{*} p<0.05$.
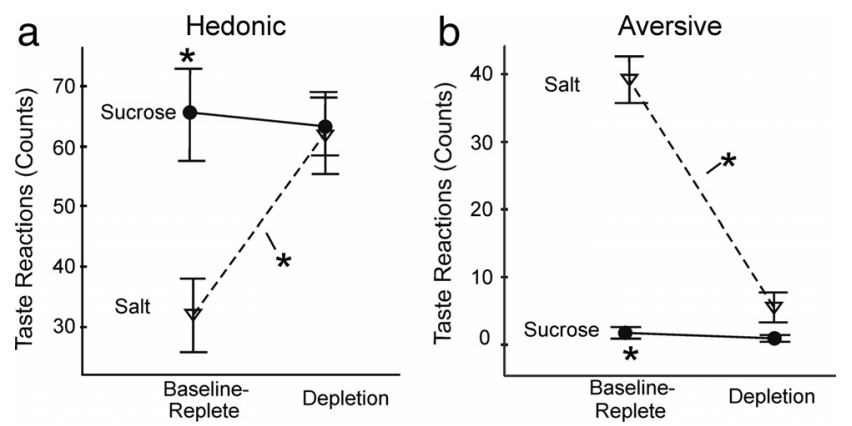

Figure 7. Taste reactivity to UCS actual taste infusions. $\boldsymbol{a}, \boldsymbol{b}$, Sucrose taste elicited stronger positive hedonic reactions $(\boldsymbol{a})$ on the normal homeostasis test of day 1 , when $\mathrm{NaCl}$ taste instead elicited many negative aversive reactions $(\boldsymbol{b})$. Conversely, after sodium depletion on day $2, \mathrm{NaCl}$ elicits predominantly positive hedonic reactions, similar to the sucrose taste.

itory trough in prolonged firing that fell statistically below baseline during most of the $5 \mathrm{~s}$ tone (Fig. $4 a$, gray shaded region) $(p=0.007, \mathrm{df}=25)$, but did not do so on the sodium-depleted day (i.e., no inhibitory $4.5 \mathrm{~s}$ trough after the phasic $0.5 \mathrm{~s}$ excitatory peak to $\left.\mathrm{CS}_{\text {salt }} ; p=0.055, \mathrm{df}=38\right)($ Fig. $4 b)$.

\section{Rate changes to UCS omission}

In extinction tests ("CS only"), the moment a taste UCS would have occurred during training represents a UCS omission at $5 \mathrm{~s}$ after CS + onset, a situation that permits the possibility of a negative prediction error as has been reported for mesolimbic dopamine neurons (Schultz, 2006). However, we did not observe a true prediction error in VP firing on extinction trials. Although there was a small initial decrease after $\mathrm{CS}_{\text {sucrose }}$ offset, rates at the moment of UCS omission did not differ from the precue baseline. After a CS + that elicited a strong firing peak $\left(\mathrm{CS}_{\text {sucrose }}\right.$ on both days; $\mathrm{CS}_{\text {salt }}$ on depletion days), firing rates declined from their $\mathrm{CS}+$ peak levels toward baseline at the moment of UCS omission $(p<0.005$, df $=25$ or 38$)$, but never dipped below the precue baseline.

Firing rates in rewarded trials ("CS plus UCS")

On CS-UCS reinforced trials, the firing rates to salt UCS were enhanced by sodium depletion, as well as to $\mathrm{CS}_{\text {salt }}$, whereas firing to sucrose UCS infusions and to its $\mathrm{CS}_{\text {sucrose }}$ remained equally high on both days.

The UCS tastes elicited firing rates proportional to their hedonic palatability in each physiological state. During normal ho- meostasis on the first test day, sucrose taste infusions elicited faster VP firing rates than $\mathrm{NaCl}$ taste infusions (Tindell et al., 2006) (post hoc on taste from above, $p=0.004, \mathrm{df}=25$ ) (Fig. 6). Sucrose UCS elevations exceeded 50\% above baseline within the first $1 \mathrm{~s}$ of oral infusion, and remained $\sim 25 \%$ above baseline for most of the $5 \mathrm{~s}$ duration of sucrose infusion. Salt UCS infusion did not elicit significant changes from baseline in firing when rats were in a normal homeostatic state on the first day.

After sodium depletion on the second day, this UCS rate pattern reversed so that $\mathrm{NaCl}$ taste infusions actually elicited slightly higher firing rates than sucrose taste, similar to our previous report (Tindell et al., 2006) (day/taste interaction: $F_{(2,127)}=18.946, p<0.0001$; post hoc $p<0.0001, \mathrm{df}=38$ ) (Fig. $6)$. The reversal in UCS firing rates involved both a major increase to $\mathrm{NaCl}$ taste ( post hoc $p=0.001, \mathrm{df}=63$ ), and a minor decrease to sucrose taste ( post hoc $p<0.0001, \mathrm{df}=63$ ). During sodium depletion, salt taste elicited firing peaks of $>60 \%$ above precue baseline within $2 \mathrm{~s}$, and remained $20-40 \%$ above baseline level for most of the $5 \mathrm{~s}$ infusion (as well as above sucrose UCS levels) (Fig. 6). Thus sodium depletion specifically reorganized rate coding of UCSs in a manner that reflected the new relative hedonic values of sucrose and salt tastes, similar to population coding. Firing to CSs followed the pattern described above for extinction tests.

\section{Baseline firing rates}

Sodium depletion produced no changes in absolute baseline firing rates (measured in the absence of CS or UCS stimuli: $5 \mathrm{~s}$ periods before presentations of CS cues or UCS taste infusions $\left(F_{(1,297)}=1.006, p=0.317\right.$ for extinction phases; $F_{(1,296)}=0.361$, $p=0.548$ for reinforced phases). Baselines within a trial similarly remained stable from before to after UCS taste infusions (CS only: $F_{(2,297)}=0.047, p=0.954$; CS plus UCS: $F_{(2,296)}=0.417$, $p=0.660)$. In short, VP baselines were quite stable in this experiment, and none of the CS or UCS effects described above could be ascribed to changes in baseline firing.

\section{Behavioral hedonic and aversive facial reactions to taste UCS}

The relative hedonic impacts of taste UCS stimuli was confirmed by video analyses of affective orofacial behavioral reactions. Sucrose taste infusions always elicited a high number of positive hedonic affective reactions, during both homeostasis and depletion states (e.g., rhythmic or lateral tongue protrusions, paw licking). In contrast, $\mathrm{NaCl}$ infusions elicited mostly negative aversive reactions (e.g., gapes, headshakes, forelimb flails) on the first test day when rats were in normal homeostasis. After sodium depletion, however, the $\mathrm{NaCl}$ valence reversed to predominantly positive reactions (interactions: hedonic: $F_{(2,30)}=5.991, p=0.006$, $\mathrm{df}=2$; aversive: $F_{(2,30)}=39.982, p<0.0001$ ) (Fig. 7). On the salt appetite day, $\mathrm{NaCl}$ elicited as many positive hedonic reactions as sucrose infusions (day 2 hedonic post hoc $p=0.372$, df $=15$ ). Sodium depletion caused both the number of positive hedonic reactions to $\mathrm{NaCl}$ taste to dramatically rise $(p=0.002, \mathrm{df}=31)$ (Fig. 7a), and the number of negative aversive reactions to fall to near zero $(p<0.0001, \mathrm{df}=30)$ (Fig. $7 b)$. This pattern confirmed that intensely salty taste switched in palatability from relatively 
"disliked" to "liked" as a consequence of the sodium-depleted physiological state, whereas sucrose remained constantly "liked." Generally, affective reactions were not elicited in significant numbers by CS tones without UCS tastes.

\section{Controls for motor confound: absence of movement coding by VP neurons}

To ascertain whether VP firing reflected changes in stimulus processing or motor reactions, we assessed neuronal activation during movements identified by video. VP neuronal activity was not strongly associated to any spontaneous movements such as head turns, forelimb movements or mouth or tongue movements, confirming that VP firing does not primarily code movements per se (Tindell et al., 2004, 2006). For example, only $2 \%$ of VP units that responded to CS cues were activated during spontaneous head turn movements scored outside of a CS. Even during cues or UCS stimuli, VP firing typically occurred $500 \mathrm{~ms}$ or more before any elicited movement, which may be too early for a movement-coding signal. Further, neural responses to CS stimuli were equally strong regardless of whether any observable movements occurred or not. Thus we conclude that the intensity of VP firing to stimuli did not tend to reflect movement parameters, but rather most likely reflected the motivational value features of CS tones and UCS tastes as described above.

\section{"Wanting" versus "liking" for CS}

We observed no elicitation of hedonic "liking" reactions when CSs tones were presented alone. Still, we leave open the question of whether the increase in CS "wanting" was matched by any increase in CS "liking" or hedonic impact (Fudim, 1978; Toates, 1986; Berridge and Schulkin, 1989). Lack of orofacial "liking" reactions helped prevent motor confounds in interpreting VP firing, and so was useful here for isolating cue-triggered "wanting" signals. However, pure auditory tones are not the best CSs for evoking conditioned hedonic reactions, and it remains possible that future studies using CSs with oral or gustatory components might yet reveal CS "liking" in the future (Delamater et al., 1986; Holland et al., 2008).

\section{Discussion}

Our results demonstrate that neural signals within ventral pallidum (VP) circuits encode incentive salience for a reward-predicting cue (CS), by patterns of neural firing in the reward-related anatomical hotspot of posterior VP (Smith et al., 2009). They also demonstrate that representations of incentive salience can be dynamically recomputed at the moment of cue re-encounter if the incentive value of the cue is physiologically altered. Here, we provoked recomputation that inverted the incentive value of a specific cue $\left(\mathrm{CS}_{\text {salt }}\right) . \mathrm{CS}_{\text {salt }}$ normally predicted the taste of aversive salt solution (UCS); however, by inducing sodium depletion, a physiological state that was novel to the animal, the incentive value of the salt-predicting cue was selectively enhanced. When the salt cue was suddenly re-encountered in this new salt-appetite state, neurons fired within $100 \mathrm{~ms}$ to $\mathrm{CS}_{\text {salt }}$ as vigorously as they ever did to the sucrose cue ( $\left.\mathrm{CS}_{\text {sucrose }}\right)$, nearly doubling firing rate on average during a $250 \mathrm{~ms}$ initial peak. This ability to specific recomputation of incentive value could potentially guide behavior adaptively toward "wanted" cues for a reward that would be highly "liked" at that moment.

The most important feature of our results was to demonstrate that recomputation of the cue's incentive salience was expressed by VP neurons even before the rats had ever tasted its associated salty UCS as positively "liked." The rats had not yet re- encountered the $\mathrm{NaCl}$ taste in the new appetite state when extinction tests exposed them to the $\mathrm{CS}_{\text {salt }}$ (salt cue) presented alone. Based solely on an accumulated cache of valenced associations between the salt cue and its previously unpleasant taste, therefore, VP neurons should not have exhibited firing peaks to $\mathrm{CS}_{\text {salt }}$. The change in VP firing reveals a dynamic revision of CS incentive value in the appetite state, which directly reversed the valence of previous associations. Our results provide the first direct evidence for a neural mechanism capable of such dynamic motivational transformations.

To understand why this transformation occurred and was predicted by our hypothesis, it is useful to consider how incentive salience is thought to relate to a Pavlovian CS (Robinson and Berridge, 1993; Berridge, 2001, 2007; Mahler and Berridge, 2009; Robinson and Flagel, 2009). The incentive salience of a previously learned CS is actively attributed at the moment of cue reencounter by mesocorticolimbic circuits that respond to the CS, which funnel through the VP. However, cached Pavlovian associations provide only half the input to the calculation of incentive salience. The recomputation also draws on current states of physiological appetite and satiety, and corresponding neurobiological states of mesolimbic brain systems that normally process the incentive value of relevant rewards. That combination dynamically determines the incentive salience attributed to a particular cue at its moment of re-encounter. Because the Pavlovian CS associatively takes on incentive-relevant properties of its UCS, the CS can often interact with relevant physiological states as its UCS would. As a consequence, a CS can be revalued by some physiological states, such as specific appetites, even when the state is completely novel and the UCS is absent (Krieckhaus and Wolf, 1968; Fudim, 1978; Toates, 1986; Berridge, 2001).

Applied to neuronal signals, a novel state may transform cueevoked neural representations of saltiness and endow the cued signal with a motivation value appropriate to what its UCS would carry at the moment. This can directly revalue a relevant CSeven before the UCS is re-encountered in the new state-making the cue a more potent attractor that is able to pull behavior and guide approach, or to trigger increased "wanting” of its UCS goal. Such preemptive neural coding could therefore adaptively contribute to smart and rapid guidance of behavior toward appropriate rewards in appetite states.

\section{Computational models of learning and motivation}

In more formal computational terms, an implication of our results is that the incentive salience of a Pavlovian cue may equal its previously learned value if and only if relevant physiological states are the same during learning as in subsequent tests. This conclusion is different from perspectives that equate incentive value to cached accumulations of previous learned values, such as the popular temporal difference model of reward learning (prediction error model):

$$
V\left(s_{t}\right)=\left\langle\sum_{i=0} \gamma^{i} r_{t+i}\right\rangle=\left\langle r_{t}\right\rangle+\gamma\left\langle r_{t+1}\right\rangle+\gamma^{2}\left\langle r_{t+2}\right\rangle+\cdots .
$$

If motivation simply always equaled the accumulated cache of prior rewards, then the incentive salience value of a cue would simply sum all previously learned values $\left(r_{t}\right)$ (McClure et al., 2003; Daw et al., 2005; Redish et al., 2008). But Pavlovian motivation is not so stable (Niv et al., 2006; Niv, 2007). In particular, the dynamic reversal of CS incentive salience shown here requires something more. To accomplish that reversal, Zhang et al. (2009) recently proposed a model that more accurately recomputes in- 
centive salience at the moment of cue re-encounter. That dynamic model explicitly incorporates a physiological factor $(\boldsymbol{\kappa})$ reflecting current hypothalamic and mesocorticolimbic states: Thus, a current physiological state can interact with previous associations of a CS with relevant reward $\left(r_{t}\right)$ to transform its cue-triggered incentive value $(V)$. The interaction can be encapsulated roughly as $\left(r_{t}, \kappa\right)$. The $\kappa$ factor allows the incentive salience of an associated CS to be adjusted as physiological states emerge or disappear (e.g., hungers, satiety, drug intoxication, mesolimbic sensitization, etc.). Here, the specific reversal of "wanting" triggered by the salt cue from negative to positive could be expressed via an additive interaction for $\left(r_{t}, \kappa\right)$, according to the model of Zhang et al. (2009):

$$
\tilde{V}\left(s_{t}\right)=\tilde{r}\left(r_{t}+\log \kappa\right)+\gamma V\left(s_{t+1}\right) .
$$

Cue-triggered "wanting" is thus transformed in valence and intensity by a relevant state factor. "Wanting" is also focused in an appropriate direction (e.g., toward salt), because the $\kappa$ factor is specific to its own particular CS and UCS reward combinations. Thus, a specific appetite for salt need not alter incentive computations for sucrose CSs, nor a caloric hunger state alter the value of salt CSs. Similarly, drug addicts may excessively "want" drugs most of all, whereas binge eaters particularly "want" food.

We note that other reward-related learning processes (e.g., cognitive expectations and act-outcome representations or simpler associative S-R habits) also operate alongside Pavlovianguided incentive salience, using different rules and different brain systems. Some, such as cached habits or cognitive-based instrumental learning, may require actual retasting of a revalued UCS to change (Dickinson and Dawson, 1987; Berridge, 2001; Dayan and Balleine, 2002; Dickinson and Balleine, 2002a). In contrast, the CS incentive salience dynamically changed here in advance of UCS retasting.

\section{Mesocorticolimbic circuitry}

Signals in the VP reflect circuits from other mesocorticolimbic components, including orbitofrontal and insular cortex, ventral tegmentum, and nucleus accumbens (Groenewegen et al., 1993; Kalivas and Volkow, 2005; Zahm, 2006). Salt appetite signals, such as angiotensin II and aldosterone, activate the subfornical organ, extended amygdala, and brainstem sites to recruit limbic circuits of motivation (Johnson et al., 1999; Krause and Sakai, 2007). Recruitment includes enhancement of dopamine and opioid neurotransmission in the nucleus accumbens shell and in neostriatum (e.g., reduced dopamine transporter binding and increased enkephalin mRNA expression), which might help modulate "wanting" and "liking" encoded in the firing of VP neurons (Lucas et al., 2003).

\section{VP in natural reward and addiction}

A powerful way for drugs of abuse and addiction to usurp brain circuitry of natural rewards would be to hijack VP-related circuits that evolved to dynamically modulate the motivation value of natural incentives. Although salt appetite is relatively unique as a specific appetite, the principles demonstrated here are shared by a more general class of "wanting" recomputations. The class includes several other natural appetites (e.g., food hunger, water thirst) and also addiction-related states (e.g., mesolimbic sensitization; drug intoxication) (Berridge, 2001; Robinson and Berridge, 2003; Tindell et al., 2005; Zhang et al., 2009).

The incentive-sensitization theory of drug addiction posits that drug sensitization usurps mesocorticolimbic circuits to dy- namically amplify the attribution of incentive salience to drug cues, producing excessive cue-triggered "wanting" to take drugs, just as biological sodium hunger here amplified the value of a salt cue (Robinson and Berridge, 2003; Tindell et al., 2005). In support of this convergence, we note that we previously reported drug sensitization to produce an incentive salience enhancement for a reward cue that was similar to the salt cue enhancement shown here, as a dynamic integration of $\left(r_{t}, \kappa\right)$ (Tindell et al., 2005). It also seems interesting that repeated sodium depletions may produce cross-sensitization to psychostimulant drugs (Bernstein, 2003; Clark and Bernstein, 2006). Thus natural salt appetite and drug sensitization and addiction may share underlying mesolimbic mechanisms. However, we also note a difference in that natural salt appetite enhances hedonic impact ("liking") as well as incentive salience ("wanting") for a relevant reward, whereas drug sensitization may enhance only "wanting" for targeted rewards (Robinson and Berridge, 2003; Tindell et al., 2005). Either may be sufficient to pull animals in a state of sodium deficiency toward a salt lick or pull addicts relentlessly toward drug-related cues and their addictive targets.

In conclusion, VP signals encode the current incentive salience of appropriate reward cues, in ways that can dynamically reverse a CS cue from "unwanted" to "wanted." Firing patterns of VP-related circuits may in this way adaptively modulate motivation to guide behavior toward relevant goals. As a downside, this may also create vulnerabilities to addiction to drugs that usurp the VP-related capacity for dynamic revaluation to cause excessive "wanting" for particular rewards.

\section{References}

Bernstein IL (2003) Interaction between natural motivational systems and those which respond to drugs of abuse. Appetite 41:333-334.

Berridge KC (2000) Measuring hedonic impact in animals and infants: microstructure of affective taste reactivity patterns. Neurosci Biobehav Rev 24:173-198.

Berridge KC (2001) Reward learning: reinforcement, incentives, and expectations. In: Psychology of learning and motivation (Medin DL, ed), pp 223-278. San Diego: Academic.

Berridge KC (2004) Motivation concepts in behavioral neuroscience. Physiol Behav 81:179-209.

Berridge KC (2007) The debate over dopamine's role in reward: the case for incentive salience. Psychopharmacology (Berl) 191:391-431.

Berridge KC, Schulkin J (1989) Palatability shift of a salt-associated incentive during sodium depletion. Q J Exp Psychol B 41:121-138.

Bindra D (1978) How adaptive behavior is produced: a perceptualincentive motivational alternative to response reinforcement. Behav Brain Sci 1:41-91.

Cannon WB (1932) The wisdom of the body. New York: Norton.

Clark JJ, Bernstein IL (2006) Sensitization of salt appetite is associated with increased "wanting" but not "liking" of a salt reward in the sodiumdeplete rat. Behav Neurosci 120:206-210.

Daw ND, Niv Y, Dayan P (2005) Uncertainty-based competition between prefrontal and dorsolateral striatal systems for behavioral control. Nat Neurosci 8:1704-1711.

Dayan P, Balleine BW (2002) Reward, motivation, and reinforcement learning. Neuron 36:285-298.

Delamater AR, LoLordo VM, Berridge KC (1986) Control of fluid palatability by exteroceptive Pavlovian signals. J Exp Psychol Anim Behav Process 12:143-152.

Dickinson A (1986) Re-examination of the role of the instrumental contingency in the sodium-appetite irrelevant incentive effect. Q J Exp Psychol B 38:161-172.

Dickinson A, Balleine B (2002) The role of learning in the operation of motivational systems. In: Stevens' handbook of experimental psychology, Vol 3, Learning, motivation, and emotion (Gallistel CR, ed), pp 497-534. New York: Wiley.

Dickinson A, Dawson GR (1987) Pavlovian processes in the motivational control of instrumental performance. Q J Exp Psychol B 39:201-213. 
Everitt BJ, Wolf ME (2002) Psychomotor stimulant addiction: a neural systems perspective. J Neurosci 22:3312-3320.

Flynn FW, Kirchner TR, Clinton ME (2002) Brain vasopressin and sodium appetite. Am J Physiol Regul Integr Comp Physiol 282:R1236-R1244.

Fudim OK (1978) Sensory preconditioning of flavors with a formalinproduced sodium need. J Exp Psychol Anim Behav Process 4:276-285.

Grill HJ, Schwartz GJ, Travers JB (1992) The contribution of gustatory nerve input to oral motor behavior and intake-based preference. I. Effects of chorda tympani or glossopharyngeal nerve section in the rat. Brain Res 573:95-104.

Groenewegen HJ, Berendse HW, Haber SN (1993) Organization of the output of the ventral striatopallidal system in the rat: ventral pallidal efferents. Neuroscience 57:113-142.

Heimer L, Van Hoesen GW (2006) The limbic lobe and its output channels: implications for emotional functions and adaptive behavior. Neurosci Biobehav Rev 30:126-147.

Holland PC, Lasseter H, Agarwal I (2008) Amount of training and cueevoked taste-reactivity responding in reinforcer devaluation. J Exp Psychol Anim Behav Process 34:119-132.

Johnson AK, de Olmos J, Pastuskovas CV, Zardetto-Smith AM, Vivas L (1999) The extended amygdala and salt appetite. Ann N Y Acad Sci 877:258-280.

Kalivas PW, Volkow ND (2005) The neural basis of addiction: a pathology of motivation and choice. Am J Psychiatry 162:1403-1413.

Krause EG, Sakai RR (2007) Richter and sodium appetite: from adrenalectomy to molecular biology. Appetite 49:353-367.

Krieckhaus EE, Wolf G (1968) Acquisition of sodium by rats: interaction of innate mechanisms and latent learning. J Comp Physiol Psychol 65:197-201.

Lim MM, Murphy AZ, Young LJ (2004) Ventral striatopallidal oxytocin and vasopressin V1a receptors in the monogamous prairie vole (Microtus ochrogaster). J Comp Neurol 468:555-570.

Lucas LR, Grillo CA, McEwen BS (2003) Involvement of mesolimbic structures in short-term sodium depletion: in situ hybridization and ligandbinding analyses. Neuroendocrinology 77:406-415.

Mahler SV, Berridge KC (2009) Which cue to "want?" Central amygdala opioid activation enhances and focuses incentive salience on a prepotent reward cue. J Neurosci 29:6500-6513.

McClure SM, Daw ND, Montague PR (2003) A computational substrate for incentive salience. Trends Neurosci 26:423-428.

Mickiewicz AL, Dallimore JE, Napier TC (2009) The ventral pallidum is critically involved in the development and expression of morphineinduced sensitization. Neuropsychopharmacology 34:874-886.

Niv Y (2007) Cost, benefit, tonic, phasic: what do response rates tell us about dopamine and motivation? Ann N Y Acad Sci 1104:357-376.

Niv Y, Joel D, Dayan P (2006) A normative perspective on motivation. Trends Cogn Sci 10:375-381.

Paxinos G, Watson C (2007) The rat brain in stereotaxic coordinates. San Diego: Elsevier Academic.

Pessiglione M, Schmidt L, Draganski B, Kalisch R, Lau H, Dolan RJ, Frith CD (2007) How the brain translates money into force: a neuroimaging study of subliminal motivation. Science 316:904-906.
Redish AD, Jensen S, Johnson A (2008) A unified framework for addiction: vulnerabilities in the decision process. Behav Brain Sci 31:415-437; discussion 437-487.

Richter CP (1956) Salt appetite of mammals: its dependence on instinct and metabolism. In: L'Instinct dans le comportement des animaux et de l'homme, pp 577-632. Paris: Masson.

Robinson TE, Berridge KC (1993) The neural basis of drug craving-an incentive-sensitization theory of addiction. Brain Res Rev 18:247-291.

Robinson TE, Berridge KC (2003) Addiction. Annu Rev Psychol 54:25-53.

Robinson TE, Flagel SB (2009) Dissociating the predictive and incentive motivational properties of reward-related cues through the study of individual differences. Biol Psychiatry 65:869-873.

Schulkin J (1991) Sodium hunger: the search for a salty taste. New York: Cambridge UP.

Schultz W (2006) Behavioral theories and the neurophysiology of reward. Annu Rev Psychol 57:87-115.

Siegel S (1956) Nonparametric statistics for the behavioral sciences. New York: McGraw-Hill.

Smith KS, Berridge KC (2005) The ventral pallidum and hedonic reward: neurochemical maps of sucrose "liking" and food intake. J Neurosci 25:8637-8649.

Smith KS, Berridge KC (2007) Opioid limbic circuit for reward: interaction between hedonic hotspots of nucleus accumbens and ventral pallidum. J Neurosci 27:1594-1605.

Smith KS, Berridge KC, Aldridge JW (2007) Ventral pallidal neurons distinguish 'liking' and 'wanting' elevations caused by opioids versus dopamine in nucleus accumbens. Soc Neurosci Abstr 33:310.5.

Smith KS, Tindell AJ, Aldridge JW, Berridge KC (2009) Ventral pallidum roles in reward and motivation. Behav Brain Res 196:155-167.

Tamura R, Norgren R (1997) Repeated sodium depletion affects gustatory neural responses in the nucleus of the solitary tract of rats. Am J Physiol 273:R1381-R1391.

Tang XC, McFarland K, Cagle S, Kalivas PW (2005) Cocaine-induced reinstatement requires endogenous stimulation of mu-opioid receptors in the ventral pallidum. J Neurosci 25:4512-4520.

Tindell AJ, Berridge KC, Aldridge JW (2004) Ventral pallidal representation of pavlovian cues and reward: population and rate codes. J Neurosci 24:1058-1069.

Tindell AJ, Berridge KC, Zhang J, Peciña S, Aldridge JW (2005) Ventral pallidal neurons code incentive motivation: amplification by mesolimbic sensitization and amphetamine. Eur J Neurosci 22:2617-2634.

Tindell AJ, Smith KS, Peciña S, Berridge KC, Aldridge JW (2006) Ventral pallidum firing codes hedonic reward: when a bad taste turns good. J Neurophysiol 96:2399-2409.

Toates F (1986) Motivational systems. Cambridge, UK: Cambridge UP.

Zahm DS (2006) The evolving theory of basal forebrain functionalanatomical 'macrosystems.' Neurosci Biobehav Rev 30:148-172.

Zhang J, Berridge KC, Tindell AJ, Smith KS, Aldridge JW (2009) A neural computational model of incentive salience. PLoS Comput Biol 5:e1000437. 